\title{
JULIO GARMENDIA, O LA ESTÉTICA DE LO INVEROSÍMIL
}

\author{
POR
}

GABRIEL JiMÉNEZ EMÁN

Apenas hoy, la obra de Julio Garmendia ha comenzado a ser objeto de acercamientos que intentan aclarar su sentido y su razón de ser. Cuarenta años atrás tal obra no despertaba un particular interés. Venezuela estaba sumida en una especie de guerrilla ideológica, donde los contenidos sociales debían por fuerza imponerse; era imperioso buscar en la literatura - y ello era natural - respuestas más o menos veladas a las situaciones nacionales. No estoy al punto de saber si la literatura escrita o producida durante los años sesenta llegó a cumplir ese cometido, pero al menos se afianzó en un lenguaje que elaboraba estéticamente su entorno, sobre todo en lo atinente a la formas de la novela y el verso, mientras que el cuento no vivió un momento de suficiente calibre, ni siquiera en sus proposiciones más realistas.

Fue necesario que transcurriera el tiempo para que las propuestas que tenían como base a la fantasía o la imaginación comenzaran a participar de la conciencia narrativa contemporánea en Venezuela, para conducirla a terrenos propicios a lo lúdico y lo humorístico. La llamada literatura nacional había estado apegada mucho tiempo al drama de la tierra; un drama social, esencialmente, que había recogido varios postulados del indigenismo (Azuela, Alegría) para interpretarlos y replantearlos, y cuya máxima expresión se encuentra en la novelística de Rómulo Gallegos. Con Gallegos se cumple el ciclo naturalismo-realismo-ideología nacional (en muchos casos intervenido por la ideología populista) que hubo de esperar una renovación en las obras de José Rafael Pocaterra, E. Bernardo Nudo Núñez para asistir a la superación de la dicotomía campo-ciudad, y para dejar libre el terreno a una narrativa de transición cuyos postulados se ofrecen en las décadas subsecuentes de los años setenta y ochenta.

Junto a estos escritores (y de otros, cuya conciencia marginada está a la espera de nuevas interpretaciones) se encuentra la figura atípica de Julio Garmendia. En esta breve nota intentaremos una interpretación que lo aleje de cualquier código foráneo (lo fantástico, por ejemplo, pudiera relacionarse erróneamente con los rezagos de cualquier vanguardia europea) y nos permita acercarnos al universo de este escritor parco, nacido en una región seca (el Estado Lara), que intentó descubrir en esa parquedad un tratamiento literario nuevo para los temas proverbiales de la muerte, la soledad o el amor.

En primer lugar, la austeridad narrativa de Garmendia es casi devastadora. De espaldas a cualquier programa —europeizante o latinoamericanista - pretende acercarse a ciertas 
proposiciones fundamentales: hablar con voz propia, incidir en la interioridad del ser. A tal punto siente Garmendia que sus cuentos se hallan en una situación de exilio nacional, que éstos son publicados en Francia, con prólogo de Jesús Semprum. Semprum, por demás, representa a la crítica menos académica, más heterodoxa. Semprum escribe en Nueva York, en 1925, la nota introductiva a La tienda de muñecos publicado en París en 1927. En ésta anota: "Sin zarandajas ni floreos retóricos, su prosa es sobria y clara y su verdadero mérito consiste en exponer sus ideas veladas por un manto diáfano, a través del cual vemos chispear la malicia. Ello testimonia que Garmendia concibe con claridad y precisión lo que quiere expresar o sugerir, sin la vaguedad o confusión tan comunes hoy en nuestras letras ... La fantasía de Garmendia denota poseer un íntimo orden lógico que le imprime a su producción cierta unidad intrínseca, la consistencia de una obra engendrada en la perseverante cavilación, no fortuitamente concebida en intermitentes devaneos de fiebre literaria". Tal opinión pertenece a alguien con otra visión de nuestra literatura, que atenta en cierto modo contra las cartillas del grupales de Alborada o de Válvula. Garmendia, de temperamento ensimismado, vive un tiempo en Europa, y a su regreso a Venezuela, vive en pensiones y hoteles. Precisamente uno de estos hoteles sirve de referente o escenario para su segundo volumen de cuentos, La tuna de oro, publicado 24 años después del primero, en 1951. Para que un interregno tan grande se haya producido en la línea de una obra, es necesario pensar en el autor como en un lento investigador de la psique, que deseaba descender a varios niveles anímicos y existenciales para luego darles forma mediante los poderes de la sugerencia poética y de la naturaleza cambiante de lo fantástico. Y cuando el concepto de lo fantástico asoma en los libros de Garmendia, acude también un cúmulo de alegatos que buscan reafirmarlo en la conciencia lectora de la actualidad. En adelante, intentaré referirme a algunos de sus cuentos desde una voluntad de libre interpretación, pero que a su vez no puede descartar el contexto crítico donde la obra de Garmendia se ha producido.

II

Como no es intención de estas notas realizar una visión histórico-biográfica de un autor, sino indicar signos de un temperamento literario, desearía detenerme brevemente en algunos de sus textos, alternándolos dialécticamente con otros, a fin de buscar hilaciones que permitan a un lector poco familiarizado con la tradición literaria venezolana, encontrar varias pistas que pudieran indicar constantes temáticas y estilísticas del universo de este escritor, siguiendo en este caso el modo descriptivo, el cual se irá ilustrando con citas entresacadas de los mismos textos de ficción, en los cuales hablará la propia voz del narrador o de sus personajes. En este caso, no contamos con suficientes documentos verbales de Garmendia, hombre poco dado a las entrevistas y a la publicidad. Incidiremos, pues, en algunos textos de sus dos libros fundamentales con el objeto de exponer algunas líneas de desarrollo.

La tienda de muñecos está conformado por ocho cuentos. En uno de ellos, "El cuento ficticio", el autor lleva a cabo lo que podría llamarse una declaración de principios; esto es, la exploración de una estética con los debidos presupuestos teóricos, sólo que desde el propio plano de la ficción. En este texto el personaje principal es el personaje hablante, el 
yo que desea explicar al lector la naturaleza especulativa del escritor, su adhesión al linaje de los fantaseadores. A tal punto de no reconocer en el cuento a una acción propiamente dicha, ni los tradicionales nudos o desenlaces; se trata de una inquisición en la fantasía pura, en el idealismo, al cual defiende de todos los embates de la realidad. Dice: "soy nada menos que el actual representante y legítimo descendiente y heredero en línea recta de los inverosímiles héroes de Cuentos Azules de que ya no se habla en las historias, y mi ideal es restaurar nuestras primeras perfecciones, bellezas e idealismos hoy perdidos ..."

Este país del Cuento Azul es a la vez asiento de otro país, el del Cuento Improbable: "Mi incurable idealismo me incita a laborar sin reposo en esta temeraria empresa; y a la larga acabaré por probar la existencia del país del Cuento Improbable a estos mismos ficticios que hoy la niegan, y hacen burla de mi fe, y se dicen sagaces sólo porque ellos no creen, en tanto que yo creo, y porque en el transcurso de nuestro exilio en lo Real se han vuelto escépticos, incrédulos y materialistas ..."

El tono general del relato es el de una fina ironía, con la que puede hablar de sus negadores sin herirles directamente: "Mis propios detractores se acercan a alabar y celebrar mi nombre, cuando mi nombre se alaba ya por sí mismo y se celebra por sí solo. Los gordos y folletinescos poderosos que ayer no se dignaban conocerme ni sabían en qué lengua hablarme, olvidan su desdén por los cuentísticos azules ..." Obsérvese la oposición hacia lo Real: el narrador llama "ficticios" a quienes no comparten su visión. Es decir, el proceso se invierte.

En otro cuento, "Narración de las nube"s, advertimos cómo la tensión narrativa remitida a un eje accional no es aquí lo importante. Este breve cuento está dividido en seis capítulos a su vez muy breves, titulados al modo en que se solían titular las obras de caballería y las narraciones renacentistas; por ejemplo: "De cómo fui lanzado sin consulta a las Nubes en persecución de unas enaguas", lo cual indica una voluntad humorística, a través de la parodia del estilo.

Aquí aparece otro de los países de Garmendia: el país de las Nubes. El personaje que habla en primera persona, la voz preferida de Garmendia- se lanza tras unas enaguas, es decir tras una aventura amorosa: "Me lancé aquel día, sombrero en mano, para atraparlas como si fueran posibles mariposas, y fui yo mismo arrebatado por el torbellino que provocaba estos estragos y empujado por el viento hacia las Nubes. De este modo salí de la existencia terrestre y fui lanzado sin consulta a las peligrosas aventuras del espacio". En los subsecuentes microcapítulos, el personaje se aventura por el "poderoso Imperio de las corrientes de Aire", en el "mundo vaporoso", hasta perder el uso de la razón, aunque aquí renace: "También, por la misma causa, me hallaba privado de todo asomo de reflexión, experiencia y cordura, a tal extremo que me dejé arrastrar por una corriente de aire que me trajo de nuevo hasta la Tierra, donde actualmente estoy y donde he compuesto esta historia".

En otro cuento, "La realidad circundante", esta presente un juego ficcional entre dos personas narrativas, una observa a la otra, esa que ofrece a los pasantes un artefacto de su invención, un pequeño y sencillo aparato que el llama "Capacidad artificial especial para adaptarse incontinenti a las condiciones de existencia, al medio ambiente y a la realidad circundante". Luego que este vendedor oferta su producto a los inadaptados a la realidad circundante - es decir, otra vez a los fantaseadores - recalca que "No existe, señores y señoras, incapacidad de adaptación a la realidad circundante capaz de ofrecer resistencia 
durable a la eficaz acción de mi aparato ajustador", mientras el narrador, asomado por encima del círculo de oyentes, asoma la cabeza para ver el aparato, y el vendedor le dice en tono de confidencia: "Es el último que me queda". Logra convencer al cliente, y éste lo adquiere para tomarse "una fuerte ventaja sobre futuros neo-adaptados". Sin embargo nuestro comprador, una vez adquirido el aparato, lo tiene frente a sí en su escritorio: "Ahí está, hoy todavía, sobre la mesa donde escribo, y alguna vez me habrá servido - no lo niego- como pisapapel sobre las hojas de un nuevo cuento inverosímil". Tenemos, pues, a alguien que padece del mal crónico de fantasear.

Esta noción de cuento inverosímil es sustancial para entender la estetica literaria de Julio Garmendia. Si un cuento ficticio, por más fantástico que sea, debe ser verosímil, el autor subraya aquí el carácter inverosímil de la ficción, algo que subvierte las versiones canónicas de los argumentos de esta naturaleza, pues el concepto empleado no es el de la ficción literaria (la norma) sino el de ficción como posibilidad de elevarse por encima de la realidad inmediata (en una abierta crítica al realismo), mientras que lo inverosímil no se refiere a los aspectos poco creíbles que puedan subyacer en un argumento, sino más bien a una voluntad de hacer pervivir y otorgar rango estético a la capacidad de fantasear.

En "El difunto yo" asistimos a uno de los textos donde mejor se expone el tema de la muerte, pero desde una óptica innovadora en la que se juega con una categoría psicológica, la del alter ego. Un buen día, el personaje descubre que ha perdido su otro yo —o más bien, que éste escapa por puro fastidio de su persona. El alter ego, personificado comienza a hacer de las suyas por la localidad: se emborracha, arma broncas, no cancela las deudas, pero con las mismas ropas de diario de su contraparte: atildado, responsable, dulce esposo. Un día lo arrestan y llevan a la policía; él promete enmendarse, pues no puede probar a las autoridades su inocencia. Su otro yo llega incluso a hacerse pasar por él ante su mujer, a engañarla para acostarse y hacer el amor con ella. A causa de esto, toma la decisión extrema del suicidio. Se cuelga de una viga, colocada al lado de su loro Jacintico. Hasta en un momento tan dramático, tiene Garmendia la capacidad de la ternura: el loro esponja las plumas y lo despide con el saludo cotidiano cuando este salía a su trabajo: "¡Adiós doctor!" Luego dice: “Tengo razones para creer que mi alter ego, que sin duda espiaba mis movimientos desde algún escondrijo improvisado, a favor de las sombras de la noche, se apoderó enseguida de mi cadáver, lo descolgó y se introdujo dentro de él". El tema de la alteridad está tratado con buena dosis de humor negro, uno de los recursos modernos utilizado por nuestro autor de manera consciente, en tanto que roza planos escatológicos, dejando en el lector un sinsabor de la injusticia, muy lejos del "final feliz". Este recurso del humor cruel aparece también en "El alma", donde el mismísimo Satán viene a reclamar el alma de un personaje que desde un principio duda de tenerla; sin embargo, el Diablo le convence, argumentándole que, en caso de tener alma le asegurara revivirlo de nuevo, y expandirlo en "infinitas perspectivas extraterrenas y visiones terrestres e infernales"; pero si careciera de ella "ésta se reducirá a un sueño denso del que no conservarás memoria". Cito un párrafo donde se advierte claramente la intervención del humor negro: "Acepté el ingenioso expediente imaginado por Satán, quien me estranguló de manera,afectuosa, en medio de la amistad más cordial y el compañerismo más estrecho, una noche del mes de enero, en el rincón de una plaza pública, a la sazón desierta bajo la luna clara y redonda". 
El tema de la muerte aparece en el segundo libro de Garmendia, La tuna de oro, en el relato titulado "El médico de los muertos", cuya acción la protagonizan nada menos que los muertos en un camposanto clausurado, donde desde hace mucho tiempo no entra nadie del mundo de los vivos, ni siquiera a llevarles flores, de lo cual se quejan. Un día descubren leyendo dificultosamente "a la luz de sus propias cuencas vacías", el epitafio del celador del cementerio, Pompilio Udano, quien les anuncia la existencia de un médico que les cuida a todos, examinándoles; hasta hallar en alguno de ellos peligrosos síntomas de vida, e indicándoles tratamientos que les permitan llevar una sana vida de muertos. Retornan a sus tumbas, pero al contrario de lo que pensamos, en ellas no habrá paz. "Ya sé lo que es vuestra paz, ya sé lo que es vuestro descanso. ¡Momentánea pausa, efímero intermedio!”, concluye en tono tétrico.

Sin duda, los temas de la muerte y del doble tienen en nuestro narrador un fuerte ingrediente romántico, tamizado por cierta escatología y conducido por un frisson de sugerencia poética.

En La tuna de oro la entonación lírica de Garmendia se halla aún más acusada, sobre todo en las piezas "Las dos chelitas", "El temblor de media noche", "Manzanita" y "Guachirongo". En estos cuentos, el escritor practica una suerte de estilo naïf, de amplias descripciones. En "Guachirongo", describe los trazos caprichosos de las nubes (otra vez las nubes, símbolos de la imaginación libérrima), los cuales describen a su vez la imagen de una leyenda, la de Guachirongo, hombre harapiento que baila y baila frente a las nubes del crepúsculo de su ciudad, "una ciudad muy celebrada por sus puestas de sol, por la majestad y belleza de sus crepúsculos", la cual bien podría ser Barquisimeto.

"Manzanita" se desarrolla al amparo de la alegoría. Esta vez son las frutas quienes encarnan la acción, en su aventura desde la granja hasta la frutería. Manzanita es nuestra fruta criolla, pequeña, un tanto inferiorizada por las frutas grandes, vistosas y olorosas. La manzanita nuestra, aunque discreta, no perece tan rápidamente por el calor o los cambios de clima. Una vindicación de nuestro suelo, de nuestra simiente. Y con qué sutileza. Los frutos o plantas alegorizados alcanzan un nivel emblemático en La tuna de oro. Basta figurarse a un hotel con este nombre, luciendo una inverosímil tuna color de oro en una fachada que alberga en su interior las situaciones menos usuales, bajo cuyas enrarecidas atmósferas y aires vetustos se mueven estos inquilinos, casi desasidos de sí. Sin embargo, en este cuento está presente uno de los puntos de vista más "distanciados de nuestro narrador, el de observador impertérrito, que mira a sus compañeros de hotel con un lente de aumento y una objetividad casi crispante, al punto de tomar la decisión de abandonar el hotel a causa de la poesía. Peñuela, nuevo huésped de La tuna de oro, se pasa más de la mitad de cada mes "en estado de lírica embriaguez", fastidiando a sus vecinos con la lectura de sus versos, cuando no está borracho o arrellanado en un sofá. Aquí, Garmendia lleva a cabo una crítica - muy velada pero muy certera- a la enfermedad de la poesía, al vicio del versificador engolado e ignorante, caprichoso o temperamental, que suele vivir en muchos ambientes de nuestra provincia. Y con ello, acaso se burla Don Julio de la fácil cursilería del romanticismo tardío.

En cuanto al otro cuento que da título a su primer libro, La tienda de muñecos, el autor introduce la narración en el terreno de lo apócrifo, declarando que no sabe "cuándo, dónde ni por quién fue escrito el relato" y que es la casualidad la que pone esas páginas en 
sus manos. En éste se lee que en esa tienda, legada por el abuelo antes de morir, hay, debidamente clasificada, una cantidad grande de muñecos. Allí trabajan, además del narrador de la historia, su padrino y Heriberto, un idiota a quien poco falta para parecerse a uno de esos muñecos; éste llora al final el remate de una tienda que apenas tiene compradores.

III

Esta descripción sucinta de algunos cuentos del escritor larense apenas desea señalar algunos temas, e indicar momentos de su peculiar estilo. Los estudios críticos sobre su obra no se han hecho esperar en los últimos años, acercamientos que abarcan aspectos textuales, historiográficos y teóricos, tanto desde perspectivas globales o específicas. Sus cuentos ocupan puesto preminente dentro de la vanguardia narrativa hispanoamericana y han influido decisivamente en las concepcioncs narrativas de su país. La faceta que hemos observado aquí - - el boceto de construcción de una estética de lo inverosímil - es apenas una de las tantas caras que esperan ser analizadas en la obra de este escritor atípico y reacio a los encasillamientos que fue Julio Garmendia; una obra en vías de ser valorada en una justa dimensión; máxime si se toman en cuenta los textos publicados en nuevas ediciones póstumas, las cuales dan cabida no sólo a sus textos de ficción, sino también a crónicas, artículos, poemas y semblanzas de algunos de nuestros principales escritores, a quienes se acerca con un tono igualrnente fresco y desenfadado, que es acaso la manera cómo a él le hubiera gustado que le vieran. Él, que guardaba dentro de sí varios países imaginarios, hizo un esfuerzo, lacónico como era, para desprenderse de ellos y darles forma, legándonos así uno de los estilos más humanos de toda la literatura venezolana. 